\title{
The preference-for-signaled-shock phenomenon: Fifty days with scrambled shock in the shuttlebox
}

\author{
GERALI) B. BIEDERMAN and JOHN J. FUREDY \\ University of Toronto, Toronto, Ontario, Canada
}

\begin{abstract}
In humans, recent direct investigations of the preference-for-signaled-shock (PSS) phenomenon in over 500 subjects have failed to confirm the existence of this phenomenon. In rats, to whom relatively strong shocks can be given, the evidence is contradictory, and much of it is methodologically confounded. However, a recent shuttlebox study which was free of such confoundings obtained a clear demonstration of PSS in three subjects and suggested that amount of training or experience with the alternatives may be critical for animal PSS. In the present study, the aim was to increase the amount-of-training variable extensively and to use enough subjects to allow valid statistical assessment of the results. Fourteen rats were therefore trained for 50 days in a shuttlebox preparation which pitted time spent in a signaled unmodifiable shock condition against time spent in unsignaled unmodifiable shock. No significant group preference emerged for the total sample, although individual subject demonstrations of an orderly preference for signaled and unsignaled shock were possible. Accordingly, while amount of training may be important for successful demonstrations of stable preference for signaled or unsignaled shock, the training variable does not appear to be relevant for determining group PSS. Insofar as group data are concerned, current evidence suggests, then, that, when methodological confoundings are removed, neither humans nor animals should be expected to yield PSS. In fact, new unconfounded evidence in the animal literature, using valid statistical assessment, suggests that under some conditions unsignaled shock is clearly preferred to signaled, inescapable, unmodifiable shock.
\end{abstract}

The preference-for-signaled-shock (PSS) phenomenon is relevant to behavioral interpretations stressing the importance of preparatory responses (c.g., Perkins, 1968), safety (c.g., Seligman, 1968), and information per se (Berlyne, 1960).

The information hypothesis holds that neutral stimuli acquire reinforcing propertics not simply through pairing with primary reinforeement but because they provide relevant information about such events (D'Amato, 1974, p. 90). A typical summary of the status of the preference-for-signaled-shock literature is given by the same author: "Taken as a whole |experiments] ... dealing with aversive stimulation, secm to offer striking support for the information hypothesis." This belief is widely held despite the evidence from over 500 human subjects to the contrary (cf. Furedy, 1975). The animal literature with its more realistic use of relatively high pain levels provides methodologically unsatisfactory evidence. Support for the existence of PSS was first reported in a shuttlebox preparation in the 1960 s by a number of investigators (e.g., Lockard, 1963; Perkins, Seymann, Levis, \& Spencer, 1966) with time spent in the signaled-

This study was supported by grants from the University of Toronto Health Sciences Committec and the National Rescarch Council of (anada to (;BB. We thank (i. A. lleighington for technical assistance. Reprints may be obtained from (i. B. Biederman, Division of Life Sciences, Scarborough (ollege, University of Foronto, West Ilill, Ontario, Canada. shock compartment as the critical index of preference. However, as detailed elsewhere (Biederman \& Furedy, 1970), the theoretical importance of these reported PSS phenomena is diminished by the possible role of modification factors introduced by the fact that the PSS evidence was based primarily on experiments which used unscrambled shock grids, thus permitting unauthorized escape and/or avoidance of the supposedly inescapable, unavoidable shocks. More recent studies have emphasized the critical role of modification in the PSS phenomenon by showing that scrambling the grids not only reduced but eliminated the PSS phenomenon, both in a symmetrical two-bar choice situation (Biederman \& Furedy, 1973) and in the shuttlebox (Furedy \& Biederman, 1976). In addition, this indirect evidence for the role of modification in the PSS phenomenon was further supported by more direct evidence that, in both the two-bar and shuttlchox situations, development of (continuously monitored) unscrambled shock modification was associated with development of PSS.

Nonsymmetrical changeover evidence strongly supporting PSS has been reported by Badia and his co-workers (Badia, Coker, \& Harsh, 1973; Badia \& Culbertson, 1972; Badia, Culbertson, \& Harsh, 1973). This evidence (which includes changeover to stronger, longer, and denser signaled shock from weaker, shorter, and less dense unsignaled shock) is unfortunately mute with respect to preference for signaling, inasmuch as 
a confounded choice strategy is used. As pointed out elsewhere (Furedy \& Biederman, Note 1), use of an active response (barpress) to change over and a passive response (withholding barpress) to remain in the normally unsignaled state is not analogous to a symmetrical barpress (Biederman \& Furedy, 1973) or shuttlebox paradigm where behavior may be appropriately connected with preference. In addition, Furedy and Biederman (Note 1) reported a failure to replicate the changeover evidence of Badia and associates and also report technical problems which suggest that shock may have been modifiable in the Badia and associates' apparatus, an eventuality which would clearly render their methodologically confounded changeover evidence irrelevant for problems involving signaling unmodifiable, inescapable shock.

A factor which may have been responsible for the Toronto laboratory's consistent failure to obtain PSS with unmodifiable shocks, both in symmetrical two-bar choice situations and in the shuttlebox context, is amount of training. The pattern of results obtained does not strongly suggest this possibility, as there was no evidence of any systematic increase in PSS over days in unmodifiable-shock choice conditions (Biederman \& Furedy, 1973, Experiment I; Furedy \& Biederman, 1976, Experiments I and II). Nevertheless, both the Lockard (1963) and Perkins et al. (1966) studies which reported PSS used at least 6 days of training, whereas the Toronto studies used only 2 days. Moreover, Miller, Daniel, and Berk (1974), who have specifically raised this amount of training factor as a possibility, tested their subjects for more than 20 days and reported little or no PSS over the first 3 days but clear PSS during later days of training. In addition, the demonstration of PSS by Miller et al. (1974) was one in which modification was ruled out by the use of tail shock. However, unlike all the other cited studies, statistical evaluation of the Miller et al. (1974) study is problematic, both because of the small number of subjects reported $(\mathrm{N}=3)$ and because of the relatively large number of subjects $(\mathrm{N}=4)$ eliminated from analyses because of "developing the tail-biting syndrome" (Miller et al., 1974, p. 274). Nevertheless, as a demonstration of PSS with clearly unmodifiable shock and a relatively long period of training, the Miller et al. (1974) experiment seems at least to suggest that the amount of training variable warrants further examination.

The present study was directed to this issue by testing animals for 50 days in the shuttlebox. In addition, a relatively large sample $(\mathrm{N}=14)$ was used, as in the studies of Lockard (1963) and Perkins et al. (1966), providing a more precise test of the null hypothesis. Shock modification was prevented by scrambling the grid rather than by a fixed-electrode tail-shock technique. The two reasons for this were that (1) scrambling appears to be as effective as the tailshock preparation in eliminating modification (Biederman \& Furedy, 1973, Experiment I), and
(2) fixed-electrode preparations, whether earclips (Perkins et al., 1966, Experiment V) or tail attachments (Miller et al., 1974), seem to be difficult to maintain, especially in long-term studies.

\section{METHOD}

\section{Experimental Design}

There are two methodological issues in the shuttlebox situation. The first concerns the stimulus arrangement for the unsignaled side, the second concerns whether or not subjects should be "acquainted" with the two alternatives each day by being confined on each side for "pretraining" sessions before testing in the free-shuttle arrangement. On the first issue, it was decided to omit the tone-light signal completely on the unsignaled side, following Lockard's (1963) original method, and in contrast with the shock-signal arrangement used in all the other cited shuttlebox studies. The Lockard design was followed on this point because this study attained the highest mean levels of PSS (approaching 90\%) with an adequate sample size (over 12). However, of course, the shock was delivered through scrambled grids to eliminate modification in the present study. On the issue of whether to provide pretraining sessions, the decision was not to use these because of evidence with modifiable shocks that pretraining reduced the amount of PSS (Furedy \& Biederman, 1976, Experiments I and II) in the shuttlebox preparation.

\section{Subjects}

Sixteen male experimentally naive rats of the Wistar strain (90 days old at the start of the experiment) served as subjects. The data of two subjects were eliminated from any analysis because of an external power failure which disrupted timing circuits on their 14th day of training; thus 14 subjects served for the entire 50-day training period.

\section{Apparatus}

Two shuttleboxes were used and constructed according to specifications given by Perkins, Levis, and Seymann (1963). This apparatus included a rectangular box with a removable center partition; preference for one compartment over the other was measured by the percentage of time spent on that side. Time spent on each side was recorded by independent electromechanical running time meters. The scrambled shock was $.6 \mathrm{~mA}$ delivered through foot grids from a Grason-Stadler shock generator/grid scrambler (Model E6070B). A compound warning stimulus was used consisting of both an $80-\mathrm{dB}$ tone from a Mallory Model SC628 audio oscillator and the onset of ceiling 28-V light bulb, shielded so that it illuminated only the compartment occupied by the subject. Shielding was accomplished by encasing light bulbs in opaque Plexiglas on top of each half of the chamber with the opening of the shield pointing toward the end of each chamber. The bulb was situated above the transparent Plexiglas ceiling. For all experiments, the boxes were housed in sound-attenuating insulated opaque containers with one-way observation windows on top and a fan to maintain air circulation. All stimuli and interstimulus intervals were automatically programmed.

\section{Procedure}

On each day subjects were allowed free shuttling between two compartments. In each compartment 5-sec duration shocks were delivered in a response-independent variable interval 120 -sec schedule (ranging from 60 to $180 \mathrm{sec}$ ). In the signaledshock compartment, tone-light signals were $3 \mathrm{sec}$ in duration, and the interval between tone-light and shock onsets was also $3 \mathrm{sec}$; that is, the tone-light signal preceded shock onset in a 3-sec CS-US delay-conditioning paradigm. In the unsignaled compartment, shock was presented with no accompanying 


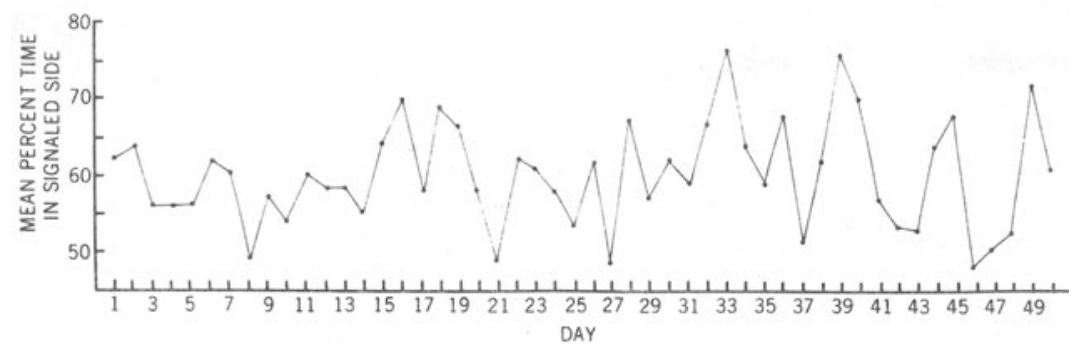

Figure 1. Preference for signaled-shock condition as a function of percentage of time spent in signaled side over 50 days $(\mathbf{N}=14)$.

stimuli. Subjects were allowed to choose freely between compartments for $3 \mathrm{~h} /$ day for 50 days. Signaled side was counterbalanced across subjects. Each subject was run in the same chamber under the same stimulus arrangement for each of the 50 days of training.

\section{RESULTS AND DISCUSSION}

Figure 1 shows the mean day-by-day preference for all subjects measured as time spent on the signaled side. There is a trend for the mean to be above 50\%, but there is clearly no sign of any orderly development of the PSS phenomenon under these long-term training conditions. Moreover, despite the large number of measured points (days) and the size of the sample involved, a statistical test based on overall performance for all subjects did not allow rejection of the null hypothesis of no preference (i.e., 50\% time spent on signaled side), $t(12)=1.82$. Because this $t$ value approaches significance, acceptance of the null hypothesis is also probably unwarranted, but it is at least clear that the strong PSS effect reported by Lockard (1963) and by Miller et al. (1974) did not emerge here.

To check whether the PSS may, after all, have developed over time, as was suggested by Miller et al. (1974), the 50 days of the present study were collapsed into 10 5-day blocks, as shown in Figure 2. A trend analysis applied to these data showed no significant linear, quadratic, cubic, or quartic effects, Fs $<1.02$. These results, taken together, indicate that, when the shock is made unmodifiable through scrambling but subjects are run for a considerable length of time, the overall PSS effect that emerges is, at best, a disorderly trend which is not sufficiently robust to achieve statistical significance with a sample size of 14 subjects.

The present investigation of the PSS phenomenon did not support its existence as a reliable group effect. On the other hand, the data gathered here do permit "demonstrations" of PSS, as in the performance of two subjects in Figure 3, who show a relatively orderly development of PSS. However, an analogous "demonstration" of the development of preference for unsignaled shock can also be obtained from the present data, as in the performance of two other subjects shown in Figure 4. The data presented in Figures 3 and 4 suggest that there are preference phenomena which develop over time within subjects, but, as Figures 1 and 2 indicate, there is no statistically consistent group phenomenon when the time spent of all subjects is evaluated.

In following Lockard's (1963) methodology of omitting the signal on the unsignaled side rather than, for example, providing the signal to follow the shock (e.g., Perkins et al., 1966), it should be recognized that we probably biased the experiment in favor of a PSS rather than a preference-for-unsignaled-shock outcome. Specifically, this arrangement is asymmetrical in terms of stimuli present on the signaled vs. unsignaled sides, and there is evidence that weak tones and lights are reinforcing (e.g., Berlyne, 1960) as well as being preferred in the presence of shocks in an analogous arrangement (Biederman \& Furedy, 1973, Experiment II). However, the results indicate that this (probably slight) bias toward a PSS outcome was not sufficient to produce a clear PSS effect when, in contrast to the Lockard (1963) arrangements, the modifiability factor was eliminated through scrambling.

Although, as noted at the outset, most current theories of behavior predict PSS (so that there is often a tendency to seek to "demonstrate" the phenomenon rather than to investigate whether or not it occurs), there are other hypotheses with a respectable background (Hull, 1943) which lead to predicting a preference for unsignaled shock. Both Furedy and Doob (1971, p. 263) and Miller et al. (1974, p. 273) have drawn attention to notions of "conditioned fear" and "conditioned aversion to the signal," respectively, notions which stem from the recognition that the signal may not have only beneficial effects and that there may, therefore, be factors which work against finding a PSS phenomenon. The conditioned fear

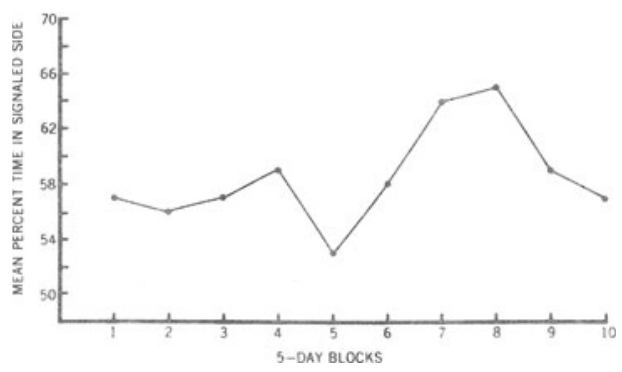

Figure 2. Preference for signaled-shock condition as a function of percentage of time spent in signaled side over 50 days in 105 -day blocks $(N=14)$. 


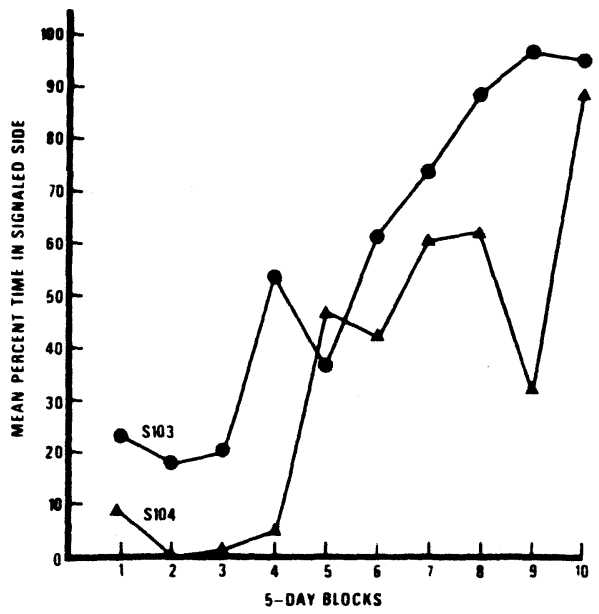

Figure 3. Preference for signaled-shock condition for two subjects (103 and 104) over 50 days in 105 -day blocks.

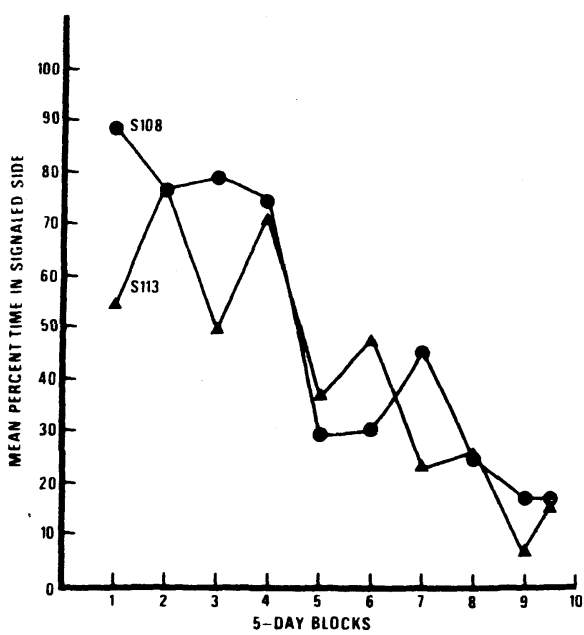

Figure 4. Preference for signaled-shock condition for two subjects (108 and 113) over 50 days in 105 -day blocks.

notion would suggest that fear, as a secondary drive, increases the impact or aversiveness of signaled shock, and thereby makes unsignaled shock preferred. Indeed, strong support for a PUS outcome in the shuttlebox has recently been published by Arabian and Desiderato (1975). In one arrangement, these workers pitted a shock signaled by $5-\mathrm{sec}$ tones, indicating precisely when shocks would appear, and a 10-min light defining shock danger periods against random tones in the 10-min shock danger period and found a strong preference for the latter relatively unsignaled condition.

Clearly, it is preferable to concentrate on investigating the conditions under which PSS does and does not occur, rather than try to provide demonstrations of PSS as if that phenomenon were something that is inevitable if only "one does it right." The contribution of the present study to that search for the conditions of occurrence is to indicate that long-term experience per se is not a relevant condition.

\section{REFERENCE NOTE}

1. Furedy, J. J., and Biederman, G. B. Methodological problems in evaluating rat preference for signaled or unsignaled shock. Paper read at the meeting of the Psychonomic Society, November 1974.

\section{REFERENCES}

Arabian, J. M., \& Desiderato, O. Preference for signaled shock: A test of two hypotheses. Animal Learning \& Behavior, 1975, 3. 191-195.

Badia, P., \& Culbertson, S. The relative aversiveness of signaled vs. unsignaled escapable and inescapable shock. Journal of the Experimental Analysis of Behavior, 1972, 17. 463-471.

Badia, P., Coker, C., \& Harsh, J. Choice of higher density signaled shock over lower density unsignaled shock. Journal of the Experimental Analysis of Behavior, 1973, 20, 47-55.

Badia, P., Culbertson, S., \& Harsh, J. Choice of longer and stronger signaled shock over shorter and weaker unsignaled shock. Journal of the Experimental Analysis of Behavior, 1973, 19, 25-32.

Berlyne, D. E. Conflict, arousal, and curiosity. New York: McGraw-Hill, 1960

Biederman, G. B., \& Furedy, J. J. The preference-forsignaled-shock phenomenon: Signaling shock is reinforcing only if shock is modifiable. Quarterly Journal of Experimental Psychology, 1970, 22, 681-685.

Biederman, G. B., \& Furedy, J. J. Preference-for-signaledshock phenomenon: Effect of shock modifiability and light reinforcement. Journal of Experimental Psychology, 1973, 100, 380-386.

D'Aмато, M. R. Derived motives. Annual Review of Psychology, 1974, 25, 83-106.

FUREDY, J. J. An integrative progress report on informational control in humans: Some laboratory findings and methodological claims. Australian Journal of Psychology, 1975, 27, 61-83.

Furedy, J. J., \& Biederman, G. B. Preference-for-signaledshock phenomenon: Direct and indirect evidence for modifiability factors in the shuttlebox. Animal Learning \& Behavior. 1976, in press.

Furedy, J. J., \& Doob, A. N. Autonomic responses and verbal reports in further tests of the preparatory-adaptiveresponse interpretation of reinforcement. Journal of Experimental Psychology, 1971, 89, 258-264.

Hull, C. L. Principles of behavior. New York: AppletonCentury-Crofts, 1943.

LOCKARD, J. S. Choice of a warning signal or no warning signal in an unavoidable shock situation. Journal of Comparative and Physiological Psychology, 1963, 56, 526-530.

Miller, R. R., Daniel, D., \& Berk, A. M. Successive reversals of a discriminated preference for signaled tailshock. Animal Learning \& Behavior, 1974, 2, 271-274.

PERKINs, C. C., JR. An analysis of the concept of reinforcement. Psychological Revien', 1968, 2, 155-172.

Perkins, C. C., Jr., Levis, D. J., \& Seymann, R. G. Preference for signal-shock vs. shock-signal. Psychological Reports, 1963, 13, 735-738.

Perkins, C. C., Jr., Seymann, R. G., Levis, D. J., \& Spencer, H., JR. Factors affecting preference for signal-shock over shock-signal. Journal of Experimental Psychology, 1966, 72, 190-196.

Seligman, M. E. P. Chronic fear produced by unpredictable electric shock. Journal of Comparative and Physiological Psychology, 1968, 66, 402-411.

(Received for publication November 10, 1975.) 